\title{
SUPLEMENTO LITERARIO
}

\section{Sonetos del mal tiempo y otros poemas}

\section{SONETO DE SEPTIEMBRE}

Dicen que es Primavera, y no me importa.

Una ebriedad de cielo claro y bueno, como si fuera en su delirio pleno el sueño largo, la tristeza corta.

Dicen que es el Amor, y no me importa.

A ratos, de relámpagos y trueno, otras, inverosímil de sereno, toda distancia su distancia acorta.

Estoy en medio de la luz del día; me dicen que es la Vida, y no me importa: no le conozco el rostro al mediodía.

Quiero la noche, siempre; la que aporta sus vestiduras de melancolía.

Me dicen que es la Muerte. Y no me importa. 


\section{JUEGO}

Amor, ni me eres fiel ni yo he de serlo. Juega tu juego libremente, afina la puntería de tu flecha, inclina el corazón herido para verlo...

Por cada blanco errado, a devolverlo: dardo por dardo contaré - mezquinapara saber cuál de ellos te conmina a dar el corazón y retenerlo.

Y no me pidas más de lo que entrega tu reticente salto equilibrista: cuando caiga la venda que te ciega, cuando en hallarme tu pasión insista, descubrirás que en el amor se juega un ágil truco de malabarista.

\section{LLAMAMIENTO}

Está el amor enfrente. Está golpeando con puño de cristal, frágil y aleve, está pidiendo que alguien se lo 1leve, al fin su cautiverio desatando.

Yo digo no. Acaso voy nombrando su nombre eterno con palabra breve, y duele el ala de la herida leve, pues aunque digo no, lo estoy llamando.

Viene a mi boca el renovado agravio; cuando voy a decirlo; está delante del corazón lo que se calla el labio, 
$y$ enmudece mi voz, sueño adelante.

- ¿Quién dijo al sueño que el callar es sabio?No sabe de perdones el infante.

\section{AnIVERsario}

Termina el día que no trajo nada.

$\mathrm{Ni}$ una seña en el aire que dijera

de la memoria de un amor cualquiera. ni una mano en el tiempo levantada.

Algo aguardaba yo de esta jornada, algo que nunca más se repitiera.

Quédame ahora sólo la frontera del día exiguo que no trajo nada.

Día de otoño cándido y liviano, con pena que no es pena, que es fatiga por este corazón como un vilano

a todo viento dando su cantiga, $y$ un dolor sin dolor, que es $\tan$ lejano, $y$ una pena sin pena, casi amiga.

\section{PIRUetA}

Amor equilibrista, compañero de mis vigilias sin ningún sentido, aire de trasnochado y mal vestido, $y$ de ti mismo el agrio carcelero:

perdona el verso juguetón y huero - no te pido perdones si te he herido, pues sólo tengo lo que tú has traído-, mas no quiero decir lo que no quiero. 
$\mathrm{Y}$ te disfrazo con mi luz secreta, te vuelvo intrascendente y casi nada; págame el drama sólo una pirueta, moneda de oro con la efigie usada. Y no reclamo más que la obsoleta palidez de una luna almidonada.

Amor es como un libro: es la portada rótulo en letras de oro, que vocea un nombre que no dice a quien lo lea nada de esa pasión encuadernada.

Muchas hojas en blanco, mucha nada; de lomo adentro, todo lo que sea una tristeza dulcemente fea y un silencio de página cerrada.

Quiere hallar el amor algo que asombre, raro infolio de autor desconocido;

sin pensar que el autor no es más que un hombre,

cambia de autor, mas con igual sentido:

un índice que tiene sólo un nombre, $y$ un ex-libris al fin que reza: olvido.

\section{AMOR PEQUEÑO}

Vaso a medio colmar, amor pequeño, trasiego de la noche, vino oscuro: de un sorbo triste su tristeza apuro, de su falsa embriaguez al fin me adueño. 
Un solo mal. Un solo llanto. Un dueño de aquel jazmín impersonal y puro. Ni llanto ni jazmín ni mal auguro, tragicomedia del amor risueño.

Si doy en preguntar — no sé cómo eranadie me da razón del acertijo. Me halló de frente y se cambió de acera,

inútilmente, pues yo nada exijo.

$\mathrm{Y}$ oculto en mi bolsillo una quimera

$y$ un capital de sueño a plazo fijo.

\section{CREENCIA}

¿De qué recuerdo he de valerme cuando al fin mi juventud sea un recuerdo?

Sé que no ha de volver lo que ahora pierdo, ni me darán lo que ahora estoy buscando.

Este es mi hoy, mas vivo regresando, y estoy en el perpetuo desacuerdo del loco corazón y el amor cuerdo, echados al camino que deseando.

Los cuatro rumbos a mi sangre pido: sur del deseo, norte de la pena, este del llanto, oeste del olvido;

por talismán un trozo de cadena, por patria el cautiverio preferido. $Y$, acaso, creerme que la vida es buena. 


\section{EPISODIO}

Cambio el amor por una baratija, le hago un guiño a la luna, digo nunca, y le perdono la cornada trunca, y no me importa más su luz prolija.

No quiero nada, nunca más, que aflija, ni una pasión que se me quede trunca. Torno a decir que nunca, nunca, nunca, y no vuelvo a entreabrir ni una rendija.

Porque mi herida es toda mi victoria, porque no guardo ni ternura ni odio, porque llevé tu nombre en la memoria,

y hoy que te olvido hasta un adiós salmodio. Porque es la vida verdadera historia y el amor nada más que un episodio.

PALABRA INÚTIL

¿A qué distancia del amor me muevo, si me invade de nuevo esta ternura que la sal de la lágrima inaugura en otro llanto que entre el pecho llevo?

Amor, ¿por qué te vivo y sobrellevo, torva pasión con la pasión más pura, blanda caricia bajo mano dura, y el sí y el no donde la sed renuevo?

Mírame descubriendo otra mirada, buscando en la palabra repetida una oculta palabra inusitada: 
ruego, esperanza, adiós, sueño o herida.

Esas palabras que no dicen nada.

Esas palabras que ya son mi vida.

\section{AYER}

Digo te quise, nunca más te quiero;

hoy eres el ayer que ya no importa, que amor eterno es la pasión más corta, y el olvido, su nombre verdadero.

Vida de cada día, mentidero de bien y mal donde la sangre acorta el largo de ala y la memoria absorta, beso fugaz y encono duràdero.

Estoy pensando en ti. En la dulzura suave de otoño que me diste un día, único cielo y única ventura,

y en seguida el adiós y la elegía, y acaso el nunca más de la ternura. Mas esa hora sigue siendo mía.

\section{RECUERDO}

Si no era el amor, lo parecía.

Traía gesto ausente, paso leve, una rosa de agosto nueva y breve y el vaticinio de la alegoría.

Si era el amor, no era de alegría. Algo como ha de ser besar la nieve, algo como un abrazo cuando llueve, como un hermano de melancolía. 
Amor, ¿ fuiste o no fuiste en mi destino, viniste a mí o no viniste, acaso?

Todo, ¿qué fue? Naufragios del camino,

dicha fugaz, llanto de otoño, ocaso, ... todo bebí como se bebe un vino. todo cabía dentro de mi vaso.

\section{DÁDIVA}

Tendré, si vuelves, para darte, acaso ese jirón de cielo; me parece que sí, te lo daré: me pertenece; también — que es mío- te daré mi abrazo;

un verso exiguo que hable de fracaso, del drama repetido en que perece siempre el amor eterno; y si no crece, el menguante con cara de payaso;

aquel mar con su noche, sí. Y alguna de todas estas cosas que enumero como jugando, como si en ninguna

arriesgase mi bien perecedero, te dirán que era toda mi fortuna un puñado de polvo verdadero.

\section{SONETO PARA TU SUEÑO}

En tu mano mi mano: así te digo con qué nombre bautizo mi quimera. ¿Qué importa que no sea verdadera, si la verdad es caminar contigo! 
Porque el amor es soledad, castigo, remordimiento de la primavera, lianto cautivo y dominada fiera, llevo la pena del amor conmigo.

De todo bien y todo mal le acuso, por todo mal y todo bien le quiero.

De acierto y desacierto igual le excuso,

y el daño triste del amor prefiero.

Róbate un beso de mi tiempo iluso para alumbrar tu sueño, pasajero.

\section{SONETO PARA TU TERNURA}

Vivo detrás de su ternura, quiero agamuzar el aire que atraviesa, y ser la eternidad en donde empieza a existir en mi tiempo verdadero.

Conmigo irá por sueño y por sendero - ¿existió alguna vez otra promesa que ésta, la de él, de la sonrisa ilesa?hasta la hora del final lindero.

No lo tengo, y es mío. Pero ampara dentro del corazón como un escudo el hombre suave que hasta mí llegara

-nunca en hora mejor llegarme pudo-. Mas si mi amor le pesa, siempre hallara fácil de atar y desatar el nudo. 


\title{
Otros poemas
}

\author{
EL RECUERDO
}

Amor del otro lado de las cosas, amor que pudo ser sobre la tierra de nuevo el paraíso, la memoria de una rosa perdida que regresa.

Estás detrás de1 aire: si yo muevo la mano puedo acariciar tu rostro, $y$ viene a mí alucinado y tierno un cielo que desciende por mi hombro.

¿Cifra cerrada de mi solo sueño, definitiva lumbre enamorada que incendia el bosque de la antigua sangre: alondra matinal que dice "es tarde", sediento ocaso que susurra "aguarda", agua clara de Dios que serpentea con su frescor selvático en la carne! Relampaguea en mi pasión tu beso, mientras la lluvia azota los tejados, $y$ es verano,

y pienso que estás lejos bajo mi lenta noche americana. 


\section{EL VIAJE VERDADERO}

Sobre este mar me marcharé a buscarte. Iré costeando nuestra orilla atlántica, dirá el norte mi aguja navegante, me cruzaré con otros argonautas y les preguntaré: - ¿Quién vive, amigos? Entre el mar y el amor, ¿a qué distancia debo arrojar, cuando al fin llegue, el ancla? $Y$ sin oírles, seguirá su andanza bajo la Cruz del Sur mi sueño intacto.

Para breve esperanza, viaje largo. Una sirena, en la mitad, me canta. No es la noche ni el alba todavía. $Y$ yo la escucho sin oír, y el agua en torno de la proa arremolina la espuma joven de la antigua gracia. Singla la nave en rutas de acechanza, y la criatura del peligro pulsa el arpa delirante del naufragio.

Sé que me salva un coro de hipocampos, una guardia callada de delfines, fieles bestias del mar, agradecidas, que buscan ramos de algas y corales, despiertan caracolas rumorosas, forman diademas con estrellas ciegas, imi cónclave de leales submarinos, para flanquear el paso a la muchacha que siempre halló en su oleaje, el compañero de la tremenda sombra y de la herida!

El mascarón de proa me señala, con el índice en alto, los luceros. Está el amor temblando entre las jarcias, $y$ todo el barco suena en los cordajes 
con invisibles músicas marinas, embanderado con un solo nombre, un solo nombre que es, Amor, el tuyo...

Apoyado mi rostro sobre el viento, la rosa sideral marca la tierra.

Estoy de pie en la nueva geografía, toca mi sangre iluminado puerto.

Sólo puedo decirte: -Esta es mi vida.

Este, mi corazón. Te los entrego.

Si dices no, la nave fatigada hacia la Muerte emprenderá el regreso.

CANTO AL AMOR

Canto al amor, su oscura maravilla, el cuerpo dócil de la gracia, el duro, despiadado ademán de la vigilia, y la ternura de la diaria entrega al insaciable oficio de la carne.

Amor de desatadas fronterías, llama de pie, arrebolada hazaña: instaura en la verdad su geografía de isla remota - abrazo hospitalarioy una paloma sin pasado vuelve a besarme los labios de la herida.

Tacto de los delirios, claro río, pánico del incendio donde empina el dios secreto aljaba involuntaria: canto el amor perenne, alucinado, su dardo de oro, el escondido fuego que mueve las mareas de la sangre. 
Canto el amor y su inmortal navío, su arboladura de éxtasis y miedos, el amor sin naufragio $y$ sin orillas, de tritón y sirenas compañero.

Vertical de mi sueño, sueño vivo, bosque del beso y la razón del bosque:

la dríada salvaje en la espesura inicia en rebelión y desafío la libertad de sonreír desnuda.

Relámpago y torrente, en la morada tibia del pecho donde se recuesta la sagrada cabeza; hilo de agua dando a la sed exigua sorbo eterno. Canto el amor incorporado en ascuas y curvo como el cielo en la caricia.

Amor, amor, amor, amor, te entrego de cuanto soy la intacta primavera; de cuanto tengo, el incendiado y nuevo delirio que en la sien relampaguea.

Cubre mi luz la orla del misterio, y el mar sellado de la doble herida para doblarse al cuerpo del deseo rompe su clausurada geometría.

Amor, amor, amor, mi dios antiguo, mi despiadado dios adolescente: ¡qué ademán de tu cólera me trajo la desmedida lumbre, jazmín breve de prisa ardiente $y$ pétalo mordido, ya nada más que aroma del recuerdo su extinguida blancura!

Amor, la rosa de los vientos dice el signo de tu abrazo. Cuatro puntos clavan en lejanías tu bandera. 
Alzas tu tienda en la mitad del tiempo y los maduros frutos se te ofrecen. Amor custodio, el del grillete tierno, amor de sumisión y de mandato, ángel de esclavizada tiranía: su aliento vivo marcha a mi costado, infatigable marcha a mi costado el lebrel de la Vida!

\section{CARta CONFIDENCIAL A ARturo TORREs-Rioseco}

Torres-Rioseco, noble amigo, un cielo que tú conoces, mas que no es el tuyo, me da la dimensión de mi desvelo, de todo cuanto en mí busco y rehuyo, y de cada imposible y cada anhelo, de todo eso que ignoro y lo que intuyo: el contraluz de bien y mal en donde la sangre joven su pleamar esconde.

Fui adolescente sin saber qué era tener el universo entre la mano, y al universo convertí en quimera, y preferí el otoño y no el verano; $y$ anduve así, ya triste y verdadera, en fuego y sombra, dialogando en vano con el murmurio de la oculta fuente que me golpea el hueso de la frente.

Amigo mío, desencuentros hube desde la iniciación de la sonrisa. Fui espectadora; y aun a ratos tuve un papel protagónico en la brisa; mas, tal la brisa, yo jamás retuve el beso breve que marchó de prisa. Siempre el mismo reloj marcó a deshora el mismo ensueño con distinta hora. 
De tal modo sumisa y agresiva, de tal modo dulcísima y violenta -contradictoria la muchacha esquiva que la aventura renovada intenta, porque sabe que sufre y está viva y en su dolor la herida se alimenta-, volví siempre los ojos hacia adentro, y allí razón de vida y muerte encuentro.

Allí el tumulto de la ola, el arco del brazo que señala los luceros, alli la proa intemporal del barco, y todos mis fantasmas marineros, alli el navío donde no me embarco, allí los nombres de mis pasajeros... Allí el cándido símbolo del viaje, nave y poema sobre el mismo oleaje.

Historia, amigo mío, sin historia: itinerario de una pena, acaso, que llevo desde siempre en la memoria, con la melancolía de un fracaso, siguiendo la obstinada trayectoria que va del corazón hasta el ocaso. Melancolía cuando cae la tarde. Melancolía que me dice: es tarde.

Estoy hundida al fin en la corriente del río eterno. Mi talismán de agua roza la sien antigua e inocente donde el recuerdo sus enigmas fragua, y acaso torno a ser la adolescente enamorada del amor del agua.

Soy la piedra en la orilla, detenida; el río corre y permanezco herida. 
Porque ignoré la gracia de ir sonriendo, fuí hasta el abismo y me volví. Detuve mi paso al borde del temor, huyendo de la caída. Por mi mal, sostuve alas de arcángel sobre el pecho ardiendo, y allí donde hubo algún sollozo, estuve. Hoy te lo digo como sé: en un canto sencillo y verdadero como el llanto.

A ti, Torres-Rioseco, te adelanto este recuento, un tramo de mi vida, mi deambular por entre sueño y canto, $y$ mis regresos con la nueva herida, culpándome de amor por tanto y tanto, quieta en la rada, nave sin partida, igual que la pasión sin el deseo, fuego sin llama y mar sin Odiseo.

¿Qué más puedo decirte? Te confío que al fin estoy amando el cotidiano tropiezo donde muere mi albedrío $y$, como Solveig, mi aguardar en vano, pero sabiendo que no hay nada mío. Guarda el secreto, amigo tan lejano y tan aproximado a mi tristeza: yo sé que en mí la Soledad empieza.

DORA IsELLA RUSSELL

Montevideo, 1955. 